\title{
DESIDRATAÇÃO DE CLARAS DE OVOS POR ATOMIZAÇÃO
}

\section{EGG WHITE DEHYDRATION BY ATOMIZATION}

\author{
Thiago Luís Magnani Grassi ${ }^{1^{*}}$ \\ Marcelo Tacconi de Siqueira Marcos ${ }^{1}$ \\ Jefferson Felipe Cavazzana ${ }^{1}$ \\ Elisa Helena Giglio Ponsano ${ }^{1}$ \\ ${ }^{1}$ Universidade Estadual Paulista, Faculdade de Medicina Veterinária de Araçatuba, Araçatuba, SP, Brasil. \\ *Autor para correspondência - thiagograssi@fmva.unesp.br
}

\begin{abstract}
Resumo
O objetivo deste estudo foi avaliar o efeito de temperaturas de desidratação por atomização sobre o rendimento e as características microbiológicas, físicas e químicas de claras de ovos em pó. Os tratamentos utilizados no experimento foram $90^{\circ} \mathrm{C}, 120^{\circ} \mathrm{C}$ e $150{ }^{\circ} \mathrm{C}$, contando com cinco repetições. O rendimento foi determinado pela relação entre os pesos da clara desidratada e in natura. As claras em pó foram analisadas quanto a umidade, proteínas, lipídeos, cinzas, estafilococos coagulase-positiva, Salmonella spp e coliformes a $45^{\circ} \mathrm{C}$. A análise da cor foi feita no sistema Lab e o $\Delta \mathrm{E}$ foi calculado a partir desses valores. Os resultados foram submetidos à análise de variância e as médias foram comparadas pelo teste de Tukey, utilizando-se nível de significância de 5\%. A temperatura de secagem influenciou a umidade das claras desidratadas mas não interferiu nos teores de proteínas, lipídeos e cinzas e nas características microbiológicas. A secagem a $150{ }^{\circ} \mathrm{C}$ proporcionou maior rendimento mas provocou escurecimento e aumento na intensidade do tom amarelo das claras desidratadas.
\end{abstract}

Palavras-chave: clara em pó; ovoprodutos; reação de Maillard; secagem.

\begin{abstract}
The aim of this study was to evaluate the yield, microbiological, physical, and chemical characteristics of powdered egg white obtained by spray drying at different temperatures. The spray drying air temperatures were $90{ }^{\circ} \mathrm{C}, 120^{\circ} \mathrm{C}$, and $150{ }^{\circ} \mathrm{C}$, with five repetitions of each treatment. Yield rate was calculated by the ratio between powdered egg white and fresh egg white. The powdered egg whites were analyzed regarding moisture, protein, lipids, ash, coagulase-positive staphylococci, Salmonella spp, and coliforms at $45^{\circ} \mathrm{C}$. Color analysis was performed with the Lab space and $\Delta \mathrm{E}$ was calculated from these values. The data were subjected to analysis of variance and Tukeys test at $5 \%$ significance. The spray drying air temperature affected the moisture of the powdered egg whites, without influencing the concentrations of proteins, lipids, and ash, nor the microbiological analyzes. The drying at $150{ }^{\circ} \mathrm{C}$ provided higher yield rate, but caused the darkening and the increase in the yellowness of the powdered egg white.
\end{abstract}

Keywords: drying; egg products; Maillard reaction; powered egg white.

Enviado em: 28 outubro de 2015

Aceito em: 31 março 2016 


\section{Introdução}

Segundo levantamentos feitos pela Associação Brasileira de Proteína Animal (ABPA) ${ }^{(1)}$, a produção brasileira de ovos em 2015 totalizou 39,5 bilhões de unidades, recorde histórico que superou em 6,1\% a produção registrada no ano anterior. Com o expressivo aumento da produção e o aquecimento do mercado interno, o consumo de ovos no Brasil em 2015 chegou a 191,7 unidades per capita, número $5,2 \%$ superior ao obtido em 2014, que era de 182 ovos $^{(1)}$. A indústria de ovos representa um expressivo segmento do mercado de alimentos devido ao valor nutricional e ao baixo custo do produto ${ }^{(2)}$, além de ofertar derivados, tais como ovos desidratados, congelados e líquidos. O Brasil, de forma semelhante a outros países produtores com pouca tradição tecnológica na área de processamento, tem enfrentado problemas de caráter técnico no desenvolvimento e na aplicação de tecnologias adequadas para os processos de secagem e conservação de ovoprodutos ${ }^{(3)}$. Segundo a ABPA ${ }^{(4)}$, o Brasil exportou, em $2014,1 \%$ de toda produção de ovos, sendo que apenas 82,2 toneladas foram de ovoprodutos desidratados.

A clara é um ingrediente muito utilizado na composição de produtos de confeitaria e padaria, merengues e produtos cárneos, devido às propriedades que favorecem a formação de espumas e géis ${ }^{(5-7)}$. Essas propriedades são atribuídas às proteínas presentes na clara, que representam $80 \%$ da matéria seca

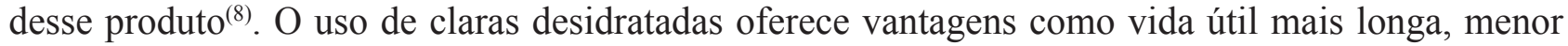
espaço para estocagem, baixos custos de transporte, segurança microbiológica, além de apresentar as mesmas propriedades funcionais das claras in natura ${ }^{(6,9)}$. No entanto, os processos de secagem incluem etapas em que o produto é exposto a elevadas temperaturas, que podem causar alterações nos componentes do ovo, principalmente nas proteínas, resultando em propriedades funcionais diferentes após a reconstituição ${ }^{(10)}$.

O processo de secagem por atomização de alimentos consta de três etapas: inicia-se com a dispersão do fluido em gotículas com o objetivo de produzir grande área superficial, seguindo para o contato das gotículas com uma corrente de ar aquecido que, em consequência, provoca a evaporação do solvente, ocasião em que as partículas sólidas são formadas. Depois disso, o produto seco é transportado por outra corrente de ar, sendo posteriormente coletado ${ }^{(11)}$.

Em geral, o uso de altas temperaturas do ar de secagem causa degradação da qualidade do produto, em termos de valor nutricional, cor e outras propriedades organolépticas ${ }^{(12)}$. Algumas modificações químicas como o escurecimento não enzimático com formação de compostos indesejáveis também podem ocorrer durante o processo de secagem ${ }^{(9,13)}$.

Neste contexto, este trabalho teve por objetivo avaliar o efeito de temperaturas de desidratação por atomização sobre as características microbiológicas, físicas e químicas de claras de ovos em pó e sobre o rendimento do processo.

\section{Material e Métodos}

Os ovos foram obtidos no comércio local, sendo de mesma marca, lote e data de produção (obtidos um dia após a postura). As claras $(2,0 \mathrm{~kg})$ foram separadas das gemas, homogeneizadas, filtradas e diluídas em água deionizada na proporção de duas partes de clara para uma de água. A desidratação foi realizada em spray dryer (LM MSD 1.0, Labmaq do Brasil Ltda, Ribeirão Preto - SP), com vazão da bomba de $0,81 \mathrm{l} / \mathrm{h}$, vazão de ar comprimido de $30 \mathrm{l} / \mathrm{min}$, variando-se apenas a temperatura do ar de secagem que foram $90{ }^{\circ} \mathrm{C}, 120^{\circ} \mathrm{C}$ e $150{ }^{\circ} \mathrm{C}$. Foram realizadas cinco repetições $(133,3 \mathrm{~g}$ de clara in natura/repetição). Após a secagem, as claras em pó foram armazenadas por 180 dias em sacos plásticos (polipropileno) que foram mantidos em recipientes de alumínio fechados, ao abrigo da luz 
e em temperatura ambiente $\left(25^{\circ} \mathrm{C}\right)$.

Para as análises microbiológicas, foram realizadas as pesquisas de estafilococos coagulase positiva (contagem direta em placas) e Salmonella spp (detecção de presença pelo método clássico) e a contagem de coliformes a $45^{\circ} \mathrm{C}$ (método do número mais provável), de acordo com as metodologias descritas por Silva et al. ${ }^{(14)}$. As análises foram realizadas imediatamente após a secagem das claras e repetidas após 30 e 180 dias de armazenamento. Essas análises foram realizadas por serem exigidas pela RDC $\mathrm{n}^{\circ} 12$ da Agência Nacional de Vigilância Sanitária (ANVISA) ${ }^{(15)}$ para ovoprodutos desidratados.

$\mathrm{O}$ rendimento foi determinado pela relação entre o peso da clara desidratada e o peso da clara in natura (x 100), conforme a Equação 1:

$$
\text { Eq. } 1 \text { Rendimento }(\%)=\frac{\text { Peso da clara em pó }(\mathrm{g}) \times 100}{\text { Peso da clara in natura }(\mathrm{g})}
$$

Para a análise proximal, as claras foram submetidas às determinações de umidade (secagem a $105^{\circ} \mathrm{C}$ até peso constante); proteínas totais (método de micro Kjehdahl; $\mathrm{N} \mathrm{x} \mathrm{6,38),} \mathrm{lipídeos} \mathrm{totais} \mathrm{(método}$ de Soxhlet) e cinzas (incineração a $550{ }^{\circ} \mathrm{C}$ ), seguindo a metodologia descrita em Horwitz e Latimer $\mathrm{Jr}^{(16)}$. Estas análises foram realizadas uma única vez, imediatamente após a obtenção das claras desidratadas.

A análise da cor objetiva das claras foi realizada imediatamente após a obtenção, por meio das determinações dos atributos L (luminosidade), $a$ (intensidade de verde-vermelho) e $b$ (intensidade de azul-amarelo) em colorímetro (MiniScan XE Plus, HunterLab, Reston - Estados Unidos). Cada atributo de cor foi medido por três pulsos consecutivos do equipamento, originando um valor médio. A partir desses valores, foi calculado o $\Delta \mathrm{E}$, por meio da equação 2 :

$$
\text { Eq. } 2 \Delta \mathrm{E}=\sqrt{\left(\Delta \mathrm{L}^{2}\right)+\left(\Delta a^{2}\right)+\left(\Delta b^{2}\right)}
$$

Para a análise estatística, inicialmente, o teste de Shapiro-Wilk foi realizado para verificar se os dados apresentavam distribuição normal e, após a constatação, os dados foram submetidos à análise de variância e as médias foram comparadas pelo teste de Tukey, utilizando-se o software Action ${ }^{\circledR}$ versão $2.9^{(17)}$. O nível de significância adotado foi de 5\%.

\section{Resultados e Discussão}

As análises microbiológicas indicaram a ausência de Salmonella, estafilococos coagulase positivos e coliformes nas claras em pó secas em todas as temperaturas testadas (Tabela 1), o que indica que os teores reduzidos de umidade impossibilitaram o desenvolvimento desses microrganismos por até 180 dias de armazenamento. Os resultados condizem com as exigências da Resolução da Diretoria Colegiada $\mathrm{n}^{\circ} 12$ da ANVISA ${ }^{(15)}$ para atestar a segurança alimentar de ovoprodutos desidratados. Grassi e Ponsano ${ }^{(18)}$ relataram ausência de coliformes, estafilococos coagulase positiva e Salmonella em gemas de ovos desidratadas a 90,120 e $150{ }^{\circ} \mathrm{C}$ por até 180 dias, indicando que a secagem por atomização se mostrou eficaz na estabilidade microbiológica para ambos os ovoprodutos em todas as temperaturas testadas. 
Tabela 1. Análises microbiológicas das claras desidratadas aos 0,30 e 180 dias após o processo de secagem por atomização

\begin{tabular}{|c|c|c|c|}
\hline \multirow[b]{2}{*}{ Temperatura $\left({ }^{\circ} \mathrm{C}\right)$} & \multicolumn{3}{|c|}{ Análises microbiológicas } \\
\hline & $\begin{array}{c}\text { Estafilococos coagulase } \\
\text { positivos } \\
\end{array}$ & $\begin{array}{l}\text { Coliformes } \\
(\mathrm{NMP} / \mathrm{g})\end{array}$ & Salmonella spp \\
\hline & & & Ausência em 25 \\
\hline 90 & Negativo & 0 & $\stackrel{\mathrm{g}}{\text { Ausência em } 25}$ \\
\hline 120 & Negativo & 0 & $\begin{array}{c}\mathrm{g} \\
\text { Ausência em } 25\end{array}$ \\
\hline \multirow[t]{3}{*}{150} & Negativo & 0 & $\mathrm{~g}$ \\
\hline & $\mathrm{n}-5$ & $n-5$ & $n-5$ \\
\hline & $c-1$ & $c-2$ & $c-0$ \\
\hline Parâmetros da Resolução da Diretoria & $\mathrm{m}-1 \times 10^{2}$ & $\mathrm{~m}-1$ & $\mathrm{~m}$-Ausência \\
\hline Colegiada $n^{\circ} 12^{1,2}$ & $M-5 \times 10^{2}$ & $M-10$ & M - Ausência \\
\hline
\end{tabular}

${ }^{l} \mathrm{n}$ - número de amostras, $\mathrm{c}$ - número de amostras permitidas entre a contagem mínima e máxima, $\mathrm{m}$ - contagem minima, M- contagem máxima.

${ }^{2}$ Fonte: BRASIL ${ }^{(15)}$

O rendimento da secagem a $150^{\circ} \mathrm{C}$ foi maior quando comparado às demais temperaturas (Tabela 2) e a explicação para esse resultado pode estar relacionada ao teor de umidade das claras desidratadas. A umidade mais elevada das claras desidratadas a $90{ }^{\circ} \mathrm{C}$ pode ter possibilitado maior aderência do produto à câmara de secagem, resultando em menor recuperação do pó, enquanto que a menor umidade das claras secas a 120 e $150{ }^{\circ} \mathrm{C}$ parece ter facilitado a remoção do pó de dentro da câmara de secagem, contribuído para o aumento do rendimento.

Tabela 2. Rendimento dos tratamentos e composição centesimal das claras desidratadas por secagem por atomização ${ }^{1}$

\begin{tabular}{cccccc}
\hline \multirow{2}{*}{ Temperatura $\left({ }^{\circ} \mathrm{C}\right)$} & \multirow{2}{*}{ Rendimento (\%) } & \multicolumn{4}{c}{ Análise proximal (\%) } \\
\cline { 3 - 6 } & & Umidade & Proteína & Cinzas & Lipídeos \\
\hline 90 & $9,42 \pm 0,08^{\mathrm{c}}$ & $7,42 \pm 0,73^{\mathrm{a}}$ & $79,44 \pm 3,24$ & $5,60 \pm 0,41$ & $3,34 \pm 1,01$ \\
120 & $9,87 \pm 0,14^{\mathrm{b}}$ & $4,76 \pm 0,12^{\mathrm{b}}$ & $80,66 \pm 0,57$ & $6,24 \pm 0,39$ & $3,54 \pm 1,85$ \\
150 & $10,33 \pm 0,34^{\mathrm{a}}$ & $5,28 \pm 0,20^{\mathrm{b}}$ & $81,60 \pm 1,49$ & $5,74 \pm 0,47$ & $3,97 \pm 1,65$ \\
\hline $\mathrm{P}$ & 0,0001 & $<0,0001$ & 0,2970 & 0,0785 & 0,8104 \\
\hline
\end{tabular}

${ }^{1}$ Médias seguidas de letras diferentes indicam diferença estatística na coluna pelo teste de Tukey, a $5 \%$ de probabilidade.

Os teores de umidade encontrados neste experimento estiveram próximos ou abaixo dos relatados em outras pesquisas realizadas com clara em pó. Handa et al. ${ }^{(19)}$ descreveram teores de umidade de claras em pó comerciais que variaram de 6,34 a $7,90 \%$. Rao et al. ${ }^{(20)}$ relataram umidade de $8,6 \%$ para claras submetidas a temperatura de secagem de $185^{\circ} \mathrm{C}$. Os teores de proteínas, cinzas e lipídeos das claras não diferiram entre as temperaturas de secagem testadas (Tabela 2). Os valores de proteína condizem com os encontrados por Ayadi et al. ${ }^{(10)}$, que relataram teor médio proteico de $79,34 \%$, e por Rao et al. ${ }^{(20)}$, que descreveram $81 \%$ de proteínas em claras submetidas a secagem por atomização.

A intensidade de vermelho das claras em pó não foi alterada pelas diferentes temperaturas de secagem (Tabela 3). Já a temperatura de $150{ }^{\circ} \mathrm{C}$ tornou o produto desidratado menos claro e mais amarelo, provavelmente em função da ocorrência da reação de Maillard. Esta reação ocorre na presença de açúcares redutores e aminoácidos em temperaturas elevadas, resultando no escurecimento do produto e na formação de flavor diferenciado ${ }^{(21)}$. Segundo Bergquist ${ }^{(9)}$, a reação de Maillard é a principal responsável pela formação de compostos que alteram a cor e odor de ovoprodutos desidratados. 
Tabela 3. Cor das claras desidratadas por atomização ${ }^{1}$

\begin{tabular}{cccc}
\hline & \multicolumn{3}{c}{ Atributos da cor ${ }^{\mathbf{2}}$} \\
\cline { 2 - 4 } Temperatura $\left({ }^{\circ} \mathbf{C}\right)$ & $\mathbf{L}$ & $\boldsymbol{a}$ & $\boldsymbol{b}$ \\
\hline 90 & $96,06 \pm 0,24^{\mathrm{a}}$ & $-0,96 \pm 0,20$ & $9,49 \pm 0,55^{\mathrm{b}}$ \\
120 & $95,83 \pm 0,46^{\mathrm{a}}$ & $-1,07 \pm 0,25$ & $9,39 \pm 1,10^{\mathrm{b}}$ \\
150 & $94,99 \pm 0,32^{\mathrm{b}}$ & $-1,12 \pm 0,18$ & $11,10 \pm 0,37^{\mathrm{a}}$ \\
\hline $\mathrm{P}$ & 0,0011 & 0,4880 & 0,0052 \\
\hline${ }^{1}$ Médias seguidas de letras diferentes na coluna indicam diferença estatística pelo teste de Tukey, a $5 \%$ de \\
probabilidade. \\
${ }^{2} \mathrm{~L}-$ luminosidade; $a-$ intensidade de verde-vermelho; $b$ - intensidade de azul-amarelo.
\end{tabular}

A diferença das cores das claras desidratadas a $150{ }^{\circ} \mathrm{C}$ em relação às obtidas a 90 e $120^{\circ} \mathrm{C}(\Delta \mathrm{E}=1,94$ e 1,91, respectivamente) foi considerada distinguível à percepção humana, de acordo com a norma DIN (Deutsche Institut für Normung) 6174(22), o que pode resultar em rejeição ao produto. Seguindo a mesma norma, a diferença entre as claras desidratadas a 90 e a $120^{\circ} \mathrm{C}(\Delta \mathrm{E}=0,27)$ foi considerada muito pequena, apresentando baixa possibilidade de detecção pelo consumidor.

Os resultados mostraram que a desidratação de claras de ovos a $90{ }^{\circ} \mathrm{C}$ apresentou menor remoção da umidade e aderência do produto final a câmara de secagem, resultando em menor rendimento. A secagem a $150^{\circ} \mathrm{C}$ acarretou em alterações na cor das claras desidratadas, devido à reação de Maillard provocada pela temperatura elevada. Devido às alterações descritas, a temperatura de $120{ }^{\circ} \mathrm{C}$ foi a mais adequada para a secagem de claras por atomização.

\section{Conclusões}

A temperatura de secagem por atomização influenciou a umidade das claras desidratadas mas não interferiu nos teores de proteínas, lipídeos e cinzas nem nas características microbiológicas. A secagem a $150{ }^{\circ} \mathrm{C}$ proporcionou maior rendimento de produto mas provocou escurecimento e aumento na intensidade do tom amarelo das claras desidratadas.

\section{Referências}

1. ABPA - Associação Brasileira de Proteína Animal. Produção de ovos do Brasil cresce 6,1\% e chega a 39,5 bilhões de unidades. Disponível em: $<$ http://abpa-br.com.br/noticia/producao-de-ovos-do-brasil-cresce-61e-chega-a-395-bilhoes-de-unidades-1550>. Acesso em fevereiro de 2016.

2. Pascoal LAF, Bento JR, Santos WS, Silva RS, Dourado LRB, Bezerra APA. Qualidade de ovos comercializados em diferentes estabelecimentos na cidade de Imperatriz- MA. Revista Brasileira de Saúde e Produção Animal. 2008; 9(1): 150-157. <http://revistas.ufba.br/index.php/rbspa/article/view/912/580>. Acesso em outubro de 2015.

3. Corrêa PC, Afonso Júnior PC, Stringheta PC, Cardoso JB. Equilíbrio higroscópico e atividade de água para ovo integral processado em "spray dryer". Revista Brasileira de Produtos Agroindustriais. 2002; 4(1): 15-22. <http://www.deag.ufcg.edu.br/rbpa/rev41/Art413.pdf>. Acesso em outubro de 2015.

4. ABPA - Associação Brasileira de Proteína Animal. Relatório anual de atividades 2014. Disponível em: $<$ http://abpa-br.com.br/files/publicacoes/c59411a243d6dab1da8e605be58348ac.pdf $>$. Acesso em fevereiro de 2016. 
5. Meszaros L, Horti K, Farkas J. Changes of hen eggs and their components caused by non-thermal pasteurizing treatments. I. Gamma irradiation of shell eggs. Acta Alimentaria. 2006; 35(2):229-236. $<$ http:// dx.doi.org/10.1556/AAlim.35.2006.2.10>. Acesso em fevereiro de 2016.

6. Lechevalier L, Jeantet R, Arhaliass A, Legrand J, Nau F. Egg white drying: influence of industrial processing steps on protein structure and functionalities. Journal of Food Engineering. 2007; 83(3): 404413. < http://dx.doi.org/10.1016/j.jfoodeng.2007.03.033>. Acesso em outubro de 2015.

7. Liu XD, Han RX, Yun H, Jung KC, Jin DI, Lee BD, Min TS, Jo C. Effect of irradiation on foamig properties of egg white proteins. Poultry Science. 2009; 88(11): 2435-2441. <http://dx.doi.org/ 10.3382/ ps.2009-00063>. Acesso em fevereiro de 2016.

8. Li-Chan ECY, Powrie WD, Nakai S. The chemistry of eggs and egg products. In: Stadelman WJ, Cotterill OJ. Egg science and technology. 4th ed. New York: The Haworth Press; 1995. p. 105-176.

9. Bergquist DH. Egg dehydratation. In: Stadelman WJ, Cotterill OJ. Egg science and technology. 4th ed. New York: The Haworth Press; 1995. p. 335-376.

10. Ayadi MA, Khemakhem M, Belgith $\mathrm{H}$, Attia $\mathrm{H}$. Effect of moderate spray drying conditions on functionality of dried egg white and whole egg. Journal of Food Science. 2008; 73(6): 281-287. $<$ http://dx.doi.org/10.11 11/j.1750-3841.2008.00811.x>. Acesso em outubro de 2015.

11. Oliveira OW, Petrovick PR. Secagem por aspersão (spray-drying) de extratos vegetais: bases e aplicações. Brazilian Journal of Pharmacognosy. 2010; 20(4): 641-650. <http://dx.doi.org/10.1590/S0102695X2010000400026>. Acesso em outubro de 2015.

12. Franke K, Kießling M. Influence of spray drying conditions on functionality of dried whole egg. Journal of the Science Food and Agriculture. 2002; 82(15):1837-1841. <http://dx.doi.org/10.1002/jsfa.1269>. Acesso em outubro de 2015.

13. Rannou C, Texier F, Moreau M, Courcoux P, Meynier A, Prost C. Odour quality of spray-dried hens' egg powders: the influence of composition, processing and storage conditions. Food Chemistry. 2013; 138(2-3): 905-914. < http://dx.doi.org/10.1016/j.foodchem.2012.11.090>. Acesso em outubro de 2015.

14. Silva N, Junqueira VCA, Silveira NFA, Taniwaki MH, Santos RFS, Gomes RAR. Manual de métodos de análise microbiológica de alimentos. 3rd ed. São Paulo: Varela, 2007. 536p. Portuguese.

15. Brasil. Agência Nacional de Vigilância Sanitária. RDC n 12 - Regulamento Técnico sobre padrões microbiológicos para alimentos. Brasília, DF: Anvisa; 2001. Portuguese. $<$ http://portal.anvisa.gov.br/wps/ wcm/connect/a47bab8047458b909541d53fbc4c6735/RDC 12 2001.pdf?MOD=AJPERES $>$. Acesso em outubro de 2015.

16. Horwitz W, Latimer Jr GH. Official methods of analysis of AOAC International. 18th ed. Gaithersburg: AOAC International, 2006.

17. Estatcamp. Software Action ${ }^{\circledR}$ 2.9. São Carlos: Estatcamp, 2015. < $\underline{\text { http://www.portalaction.com.br/ }}$ content/download-action>. Acesso em outubro de 2015.

18. Grassi TLM, Ponsano EHG. Desidratação de gemas de ovos por secagem por atomização em diferentes temperaturas. Pesquisa Agropecuária Brasileira. 2015; 50(12): 1186-1191. < http://dx.doi.org/ http://dx.doi. org/10.1590/S0100-204X2015001200008>. Acesso em fevereiro de 2016.

19. Handa A, Hayashi K, Shidara H, Kuroda N. Correlation of the protein structure and gelling properties in dried egg white products. Journal of Agricultural and Food Chemistry. 2001; 49(8): 3957-3964. $<$ http:// dx.doi.org/10.1021/jf001460e>. Acesso em outubro de 2015. 
20. Rao QC, Labuza TP. Effect of moisture content on selected physicochemical properties of two commercial hen egg white powders. Food Chemistry. 2012; 132(1): 373-384. $<$ http://dx.doi.org/10.1016/j. foodchem.2011.10.107>. Acesso em outubro de 2015.

21. Jousse F, Jongen W, AgterofW, RusselS, BraatP. Simplified kinetic scheme offlavour formation by the Maillard reaction. Journal of Food Science. 2002; 67(7): 2534-2542. <http://dx.doi.org/10.1111/j.1365-2621.2002. $\underline{\text { tb08772.x }}$ >. Acesso em outubro de 2015.

22. DIN - Deutsche Institut für Normung; DIN 6174. Farbmetrische Bestimmung Von Farbabständen bei Körperfarben nach der CIELAB - Formel. Beuth Verlag: Berlim und Köln, 1979. 